\title{
Community Centred Learning: A Pathway to Community Engagement
}

\author{
Lebogang Lorraine Phiri \\ University of South Africa, South Africa \\ Medical Research Council, South Africa \\ Natasha Hendricks \\ Medical Research Council, South Africa \\ Mohamed Seedat \\ University of South Africa, South Africa \\ Medical Research Council, South Africa
}

Address correspondence to Lebogang L. Phiri, Institute for Social and Health Sciences, University of South Africa, PO Box 1087, Lenasia, 1820, South Africa. Email: phirill@unisa.ac.za/lebops@webmail.co.za

\begin{abstract}
We report on the experiences of participants on a course which represented a pathway to community engagement. The 76 participants (20 males, 46 females), from two low-income South African communities, were part of a multi-lingual group representing English, Africans, isiZulu and Sesotho. Data were obtained from several participant group conversations. Data, analysed by thematic content analysis, showed that the engagement process during the course may have been influenced by perceived social relevance and beneficence of the course content, affirmation of situated knowledge and life experiences, the opportunities for maximum participation, and the language adopted for communication. The participants' tendency to dichotomise theory and practice seemed to have influenced receptivity to reflective components of the course. This analysis points calls for systematic studies on the value of community centred learning as engagement.
\end{abstract}

Keywords: community engagement, co-learning, capacity building

Capacity-building interventions aim to increase the self-sustaining ability of people to recognise, analyse and solve their problems, effectively control and use their own and external resources, and create new structures, approaches and values (Crisp, Swerissen \& Duckett, 2000; De Graaf, 1986). Community centred capacity-building refers to the creation of infrastructure, programme maintenance and sustainability and the problem-solving capability among individuals, organisations and groups in communities (Hawe, King, Noort, Gifford \& Lloyd, 1998). It is often achieved through a co-learning approach, which involves shared decision-making and problem-solving. Even though the actors in the learning context may be labelled as 'facilitators' and 'participants', the process is marked by co-learning in which the contributions of all are validated and valued equally (Wong, Zimmerman \& Parker, 2010).

In this report, we view community centred co-learning as a pathway to community engagement (see Eksteen, Bulbulia, Van Niekerk, Ismail \& Lekoba, this issue). Consistent with contemporary theories of learning (Mayo 2007; Merriam \& Caffarella, 1999), we believe that the community centred co-learning process is shaped by the context, philosophical orientation and tools applied in the learning environment. Unlike orthodox perspectives that tend to view capacitation and learning as a didactic one-way transmission process (see Goodley \& Lawthom, 2011), community centred co-learning as engagement is characterised by mutual respect of participants' values, affirming learning environments, recognition of situated knowl- edge and personal experiences, and participatory communication modalities (Tett, 2006).

Community Centred Learning as Community Engagement

Feminist, adult and Freirian pedagogies postulate that: (1) capacitation and learning are participatory processes in which 'participants' and 'facilitators' co-construct and co-produce knowledge that is relevant and responsive to community needs; (2) personal understandings and life experiences are valid sources of knowledge creation, and (3) dialogue about the influences of the social and macro-structures on community and individual well-being is a key element of the co-learning process (St. Germaine-Small, Walsh-Bowers, \& Mitchell, 2012). Dialogue is valued for facilitating insights and consciousness about the influences of social structures on well-being and for inspiring social change. So co-learning, as engagement, is contingent on the facilitator enabling a social environment that encourages maximum participation and participant-centred outcomes (Freire, 1970; Stake \& Hoffman, 2000). Thus, community learning is relevant to all participants concerns; affirms personal experience as a source of knowledge; encourages critical reflections about the influences of social structures on everyday life; incorporates multi-modal learning strategies to maximise participation (Bhawuk \& Brislin, 2000); and is sensitive to language as a medium of communication. Thus, framed within feminist and Freirian pedagogies, we view community centred learning as a participatory, emancipatory and transformative process (see 
Burke \& Jackson, 2007; Fetherston \& Kelly, 2007; Freire, 1970).

\section{Goals of the Study}

We sought to obtain participants' experiences of a child safety, peace and health promotion course. We aimed to understand participants' experiences as they related to relevance and beneficence, affirmation of situated knowledge, exploration of the social determinants of injuries, the use of multiple learning interactive formats and language.

\section{Course Aims, Content and Structure}

The three week course aimed to encourage participants to dialogue about the influences of social structures on childhood safety, peace and health; facilitate an appreciation for social change; affirm participants' situated knowledge and experiences of childhood well-being; maximise participation through the use of multiple learning formats; and enable expression, communication and discussions through the adoption of multi-lingualism. It utilized techniques for building rapport and relationships; interviewing skills; burns prevention and treatment; traffic safety; child maltreatment; poisoning prevention and treatment; nutrition; immunisation and economic solidarity as a means to address unemployment.

Throughout the course various formats were used, including small group discussions, audio-visual materials and story-telling, to maximise opportunities for participants to talk about their experiences and present their understandings of injuries, and injury causation and prevention. In discussions about solidarity economy, participants were offered the opportunity to draw on personal experiences of unemployment and poverty and to explore how the principles of solidarity, cooperation and equality may be operationalised to produce sustainable economic activities in their respective under-resourced communities. The course materials were presented mainly in English with facilitation in IsiZulu, IsiXhosa, Sesotho and Afrikaans.

The capacity-building and co-learning community engagement exercise we describe above is located within the pilot phase of a child safety, peace and health promotion study, which in turn is situated within a larger initiative known as the Ukuphepha Safety, Peace and Health Programme. The Ukuphepha Programme, detailed by Eksteen et al. (this issue), is focused on generating a range of trans-disciplinary and multi-disciplinary, culturally congruent and evidence-led solutions for priority injuries, including violence, across selected African countries. The Programme serves as a basis for the longitudinal study of child, male and elderly safety interventions, and is partially predicated on enacting capacity-development and co-learning as a form of community engagement. The pilot phase of the Ukuphepha Programme's child study (see Eksteen et al., this issue) was focused on testing the reliability and validity of various child risk assessment tools and obtaining insights into the experiences of participants on the training course.

\section{Method}

\section{Participants and Setting}

A total of 76 individuals were selected, from two low-income South African communities, for participation in the course. The participants, representing a convenient sample, included men and women from different linguistic groups. Their ages ranged from the early twenties to early forties and all participants had a minimum of high school matriculation. The size of the two groups is reflective of the population size of the two communities and the different levels of response to the recruitment drive across the two communities. The recruited participants did not belong to any employment agencies except being members of the communities mentioned.

\section{Data Collection and Consent}

Data were collected through two structured group conversations, a week after completion of the course. The conversations focused on participants' views about the: relevance and benefits of the course, course objectives, content formats and methods, and facilitators' approach and styles. The conversation facilitators, namely the first two authors, used probes and follow-up questions to obtain clarity and encourage deeper discussions. Even though the primary medium for the discussions was English, the multi-lingual conversation facilitator (the second author) was able to encourage discussions in Afrikaans whenever participants resorted to Afrikaans. The first author was able to do likewise when participants adopted isiZulu or Sesotho for conversation purposes. The discussions were approximately 2 hours each and were tape-recorded. In addition to the conversations, the first two authors conducted observations and recorded notes at different junctures in the course. The observations focused on the influence of language on levels of participation, interpersonal style and the overall learning environment.

\section{Procedure}

Permission was obtained from the participants to tape record the conversations and participants were assured of anonymity and confidentiality. Participation was voluntary. The recruitment for participants was conducted through local

\section{Table 1}

Description of Course Structure

Relevance and Beneficence

Introduction of multilevel interventions on safety, peace and health promotion; building rapport; relationship-building and interviewing skills; burns prevention; traffic safety; poisoning prevention; child maltreatment; nutrition; immunisation; and solidarity economy.

Macro-determinants of childhood injuries

Situated knowledges and personal experiences

Maximising learning and participation
How does society impact on childhood injuries and prevention (highlighting the links between personal and community factors as either key risk or protective factors of childhood injuries)?

What is my role in childhood injury prevention? What have I learned from my experiences and how can I be involved in change in the prevention of injuries at a personal level and community level?

Small and open group discussions; role-play; drama; videos; flip chart presentations; and storytelling. 
community centres by word of mouth, written advertisements and stakeholder networks. Project coordinators facilitated a recruitment and selection process wherein candidates were screened according to specific criteria: matriculation, basic reading and writing skills, and basic interpersonal skills. During the selection process, participants were provided with information about the project, and an opportunity to ask questions in order to promote a social contract.

\section{Data Analysis}

Thematic content analysis, involving several steps, was used to analyse the data (Braun \& Clarke, 2006). As the first step the lead author, assisted by the second author, listened carefully and repeatedly to the audio recordings. The first two authors listened to the tape-recordings thrice. The repeated act of listening to the tape-recordings and development of notes allowed the lead author to identify patterns within the data. Since the tape-recordings were not transcribed, the first two authors developed detailed notes as they listened to the tape recordings. They maintained all their notes in English and undertook oral translations for the parts of the conversations where languages other than English were used. Patterns within the data were coded and assembled into non-overlapping themes in accordance with the guidelines of Braun and Clarke (2006). Following consultation and discussions, the lead and second au thors drew on the notes made during the observations and generated themes in resonance with the aims of the exploratory study and interpretive framework of this report.

\section{Findings: Reflections on Co-Learning as Engagement}

Four main themes emerged from the thematic content analysis, which reflect the course participants' views on: content relevance and beneficence; the benefits of recognising situated knowledge and participant experiences; the utility and limitations of facilitating understandings of the macro-determinants of childhood injuries; and the value of multiple learning modalities. In addition, the first two authors drew on their observations to reflect on a fifth theme namely, the influence of language on learning during the course. We discuss each of these themes below.

\section{Perceived Relevance and Beneficence}

Overall, participants presented a positive view of the course content. The participants reported that all the course topics were relevant to priority community concerns. Participants reported that they had gained knowledge and an understanding about child safety and the hazards that may predispose children to various injuries in the home. For instance, participant \#1 said: "I did not realise there were so many things in my home that were dangerous I was not aware of...... but now I know better". The participants experienced the course content as being relevant to their daily lives. In this respect, participant \#3 suggested that, "The tools we received on relationship-building skills and safety helped us a lot and I realise that I can apply them beyond working as a field worker". Some respondents connected the course content to educational, social action and advocacy roles that they may fulfil in the community.

The social relevance of the course was illustrated by respondent \#5 who said, "I see so many young mothers in our community who don't immunise their kids because they just don't care or they don't know the importance maybe ... now I feel empowered to confidently warn them of the consequences because of the education I have received here". Congruent with previous studies (Stake \& Hoffman, 2000; Tett, 2006), course relevance seemed to have been enabled by linking the aims and objectives to participants' needs and priorities. Despite the reported relevance, participants also reported that some of the modules were too lengthy and detailed, requiring high-levels of concentration during sessions. For instance, participant \#7 pointed out that, "The part on intentional and unintentional childhood injuries was way too long, so much that I started to slumber ... so next time, please make it shorter and stick to the major facts". Such a view suggests that relevance and beneficence of the course are linked to a precise focus and brevity (Bhawuk \& Brislin, 2000).

\section{Situated Knowledge and Interpersonal Connections}

Participants reported that the course was an opportunity to draw on their personal experiences and generate knowledge and insights. Participant \#9 articulated that "You did not just talk ... you listened to what people had to say and you gave us the freedom to talk about our own experiences and that made it easy to talk because nobody knows my experiences more than me", suggesting that the course was affirming of her personal experiences.

In recognising participants' personal experiences, the course also seemed to have facilitated opportunities for interpersonal linkages and appreciation for diversity. According to participant \#11, "We were all part of a larger group but did not know about each other or our backgrounds. So talking about our experiences helped us to get to know each other and accommodate each other". The sentiments of participant \#11 suggest that the learning environment can also serve as a space for building interpersonal relationships, consistent with prior studies (see St. GermaineSmall et al., 2012; Stake \& Hoffman, 2000).

\section{Dialogues about Social Structures}

The component of the course that aimed to generate reflective discussions about the influences of the larger social context on childhood safety, peace and health obtained ambiguous participant reactions. Some, like participant \#15, appreciated the social insights the course offered, stating that "I never thought that all these injuries were connected to what we all do in our environments". However, for others, like participants \#17, despite the sense of social understanding, the focus on social determinants was experienced as "theory", "boring", and "excessive talk": "The trainer gave us an overview of the causes of childhood injuries even though theory is boring and the trainer talked and talked and talked".

In this respect, some participants may have dichotomised "action" and "theory" and may have not seen reflection as an integral feature of praxis that constructs "action" and "reflection" as a gestalt (see Seedat, this issue). So, despite the course's emphasis on promoting reflections as per Freirian and feminist pedagogies (St. Germaine-Small et al., 2012; Freire, 1970), our findings show mixed reactions. We speculate that perhaps the course structure itself entrenched a dichotomy between reflection and action in that the component focused on social determinants and context was formulated primarily as didactic input.

\section{Co-learning Modalities}

The multiple modalities allowed the participants to experience the course as an interactive, enjoyable, affirming and enabling experience. The experiential and application exercises were valued particularly for demonstrating skills required of the participants. To illustrate, participant \#21 expressed that "The 
exercises and group discussion were very useful. We were able to understand the modules practically ... I really loved the role-plays because it was a good and practical way to learn", while participant \# 23 indicated that "During the role plays, partnering with other people really boosted my confidence because it showed that I had understood what we were taught and that I was able to apply it by helping someone else who was struggling".

Story-telling was also valued for promoting learning through analogies: "Trainers were very patient and creative in explaining some of the things we didn't understand like making examples and telling stories (participant \#27). Likewise, group discussions were positively received, with participant \#31 conveying that "The group presentations were really good because even though we were scared, you told us it was okay to make mistakes ... it boosted my self-confidence because it improved my presentation skills".

The participants' self-reports are consistent with other research (see Bhawuk \& Brislin, 2000; St. Germaine-Small et al., 2012) which suggests that varied learning modalities are necessary to maximise participation, expressiveness and understanding in community centred learning environments.

\section{The Language of Learning}

While English was adopted as the primary language for study materials, observations conducted by the first two authors suggested that participants demonstrated better comprehension of the concepts when encouraged to speak in their preferred languages. Participants seemed to be far more engaged, expressive, confident and vocal when they were encouraged to communicate in their first language, resonating with previous findings (see Robinson, 2007) that demonstrate how languages of choice enable learning and communication, expression and improved confidence. These expressive qualities were noticeable when participants performed role plays in their languages of choice. The first two authors also observed that participants displayed optimal levels of confidence, expressive ability and articulation during role-plays conducted in an African language or Afrikaans.

\section{Limitations}

Our findings must be viewed with some caution as the methodology was marked by several limitations. We highlight two pertinent limitations. First, even though the data collection process, by way of the conversations, was guided by a set of questions, the large group size may have limited exploration of emerging themes and produced uneven participation. The more vocal participants may have dominated the conversations. Hence, smaller focused group discussions should be considered for follow-up analysis. Second, the data analysis process did not include sufficient measures to deal with the accuracy and veracity of thematic categories. There was no independent verification process.

\section{Conclusion}

Participants experienced the course as a form of community centred co-learning. The self-reported sense of engagement was derived from participants' perceived sense of relevance and beneficence of the course, affirmation of situated knowledge and life experiences, and the opportunities for maximum participation. The space to generate understanding through personal experience was affirming and enabled interpersonal connections and respect for difference. Participants valued the multiple and diverse formats that encouraged exploration even though some modules of the course were thought to be long and overly-detailed.

\section{References}

Bhawuk, D. P. S., \& Brislin, R. W. (2000). Cross-cultural training: A review. Applied Psychology: An International Review, 49, 162-191.

Braun, V., \& Clarke, V. (2006).Using thematic analysis in psychology. Qualitative Research in Psychology, 3, 77-101.

Burke, P. J., \& Jackson, S. (2007). Reconceptualising lifelong learning: Feminist interventions. London, England: Routledge

Crisp, B. R., Swerissen, H., \& Duckett, S. J. (2000). Four approaches to capacity building in health: Consequences for measurement and accountability. Health Promotion International, 15, 99-107.

DeGraaf, M. (1986). Catching fish or liberating man: Social development in Zimbabwe. Journal of Social Development in Africa, 1, 7-26.

Eksteen, R., Bulbulia, A., Van Niekerk, A., Ismail, G., \& Lekoba, R. (2012). Ukuphepha: A multi-level community engagement model for the promotion of safety, peace and health. Journal of Psychology in Africa, Special issue: Community engagement.

Fetherston, B., \& Kelly, R. (2007). Conflict resolution and transformative pedagogy: A grounded theory research project on learning in higher education. Journal of Transformative Education, 5, 262-285.

Freire, P. (1970). Pedagogy of the oppressed. New York, NY: Seabury Press.

Hawe, P., King, L., Noort, M., Gifford, S. M., \& Lloyd, B. (1998). Working invisibly: Health workers talk about capacity-building in health promotion. Health Promotion International, 13, 285-295.

Goodley D. A., \& Lawthom, R. (2011). Deleuze, disability and sex. In F. Beckman (Eds.), Deleuze and sex (pp.191-192). Edinburgh, Scotland: Edinburgh University Press.

Mayo, P. (2007). Critical approaches to education in the work of Lorenzo Milani and Paulo Freire. Studies of Philosophical Education, 26, 525-544.

Merriam, S. B., \& Caffarella, R. S. (1999). Learning in adulthood (2nded.). San Francisco, CA: Jossey-Bass.

Robinson, C. (2007). Context or key? Language in four adult learning programmes. International Journal of Educational Development, 27, 542-551.

Stake, J. E., \& Hoffman, F. L. (2000). Putting feminist pedagogy to the test. The experience of women's studies from student and teacher perspectives. Psychology of Women Quarterly, 24, 30-38.

St. Germaine-Small, M., Walsh-Bowers, R., \& Mitchell, T. L. (2012). Exploring the relevance of feminist pedagogy to community psychology: Continuing the dialogue. Journal of Community Psychology, 40, 129-144.

Tett, L. (2006). Community education, lifelong learning and social inclusion. Edinburgh, Scotland: Dunedin Academic Press.

Wong, N. T., Zimmerman, M. A., \& Parker, E. A. (2010). A typology of youth participation and empowerment for child and adolescent health promotion. American Journal of Community Psychology, 46, 100-114. 